\title{
Research Paper: The Effects of the Home-based Self-care Program Follow-up on Re-hospitalization Frequency and Quality of Life in Patients With Chronic Obstructive Pulmonary Disease
}

Fatemeh Pazouki Movakher $^{1}$ (D), Mohammad Saeed Khanjani2 ${ }^{* *}$ (D), Mohammad Ali Hosseini ${ }^{1}$ (D), Enayatollah Bakhshi ${ }^{3}$, Banafsheh Ebrahimi Barmi $^{1}$ (D)

1. Department of Rehabilitation Management, University of Social Welfare and Rehabilitation Sciences, Tehran, Iran.

2. Department of Counselling, University of Social Welfare and Rehabilitation Sciences, Tehran, Iran.

3. Department of Biostatistics, University of Social Welfare and Rehabilitation Sciences, Tehran, Iran.

\begin{tabular}{l|l}
$\begin{array}{c}\text { Use your device to scan } \\
\text { and readthe article online }\end{array}$ & $\begin{array}{l}\text { Citaton: Pazouki Movakher F, Khanjani MS, Hosseini MA, Bakhshi E, Ebrahimi Barmi B. The Effects of the Home-based } \\
\text { Self-care Program Follow-Up on Re-hospitalization Frequency and Quality of Life in Patients With Chronic Obstructive Pulmo- } \\
\text { nary Disease. Iranian Rehabilitation Journal. 2021; 19(2):173-180. http://dx.doi.org/10.32598/irj.19.2.1347.1 }\end{array}$ \\
dol'http://dx.doi.org/10.32598/irj.19.2.1347.1
\end{tabular}

\section{(c) (1) (8)}

Article info:

Received: 11 Feb 2021

Accepted: 19 May 2021

Available Online: 01 June 2021

Keywords:

Self-care program, Chronic Obstructive Pulmonary Disease (COPD), Re-hospitalization, Quality of life

\section{ABSTRACT}

Objectives: Chronic Obstructive Pulmonary Disease (COPD) impacts the quality of life of the affected patients. The present study aimed to determine the effects of home-based self-care program follow-up on re-hospitalization frequency and quality of life in COPD patients.

Methods: This quasi-experimental study was performed on 44 COPD patients at Masih Daneshvari Hospital in Tehran City, Iran, in 2018. For collecting the necessary data, we used demographic data checklist, COPD Assessment Test, and the St. George's Quality of Life questionnaire. We used SPSS v. 22 for analyzing the obtained data.

Results: The present study revealed that the highest age frequency was in the 61-70 years age group. Moreover, the male gender had the highest frequency and most research participants had elementary school education; the highest frequency regarding the disease duration was $>5$ years. Besides and the hospitalization frequency was once a year. The present study findings indicated that the provided self-care program follow-up reduced the re-hospitalization frequency and increased the quality of life of the explored COPD patients $(\mathrm{P}<0.001)$.

Discussion: The obtained results revealed that implementing a course of home-based followup self-care program could reduce re-hospitalization and increase the quality of life of COPD patients; thus, it is suggested that such follow-up programs be included in COPD treatment plans. 


\section{Highlights}

- In COPD patients, re-hospitalization is common, and it occurs within 1 year of the last exacerbation incidence in $>60 \%$ of the patients.

- Improper follow-up and inadequate follow-up of patients after discharge may increase the risk of re-hospitalization within one month of discharge.

- Regular remote follow-up helps patients to actively participate in the treatment process and successfully control their chronic diseases.

\section{Plain Language Summary}

Diseases, such as chronic bronchitis, emphysema, and asthma fall into the category of COPD. This disease is a major health condition and among the main causes of disability in people over the age of 40 years and the elderly. In COPD patients, re-hospitalization happens within 1 year of the last exacerbation incidence in more than $60 \%$ of the patients. In general, self-care programs fall into the category of health promotion strategies, which are often adopted for patients with chronic disorders. They are also used as solutions for solving this problem. Appropriate and adequate follow-up of patients following their discharge may decrease the risk of re-hospitalization within one month of discharge and increase their quality of life.

\section{Introduction}

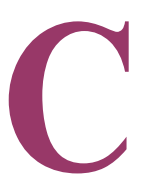

hronic Obstructive Pulmonary Disease (COPD) can impair Quality of Life (QoL) by preventing socialization and the use of entertainment by COPD patients. It also invokes despair and anger due to disability [1]. Recent research suggests that improving the quality of treatment can reduce the mortality caused by chronic diseases. A major characteristic involved in improving treatment quality is the patient's involvement in the treatment and self-care process [2]. The patient's lack of awareness about the self-care method leads to adverse health outcomes and re-hospitalization [3]. In COPD patients, re-hospitalization is common and occurs in $20 \%$ in one month and $60 \%$ in one-year post-discharge [4]. Generally, self-care programs fall into the category of health promotion strategies, i.e., often adopted for patients with chronic conditions. They are also used as solutions for preventing re-hospitalization [5].

However, considering the importance of self-care training for COPD patients, a study revealed that re-hospitalization is mainly linked to the lack of patient care; the lack of social support; low-quality care; the patients' perception of the discharge, and a lack of communication between the patient and the hospital following discharge [6].

Training and following patients after discharge play an essential role in their rehabilitation [7]. Training patients or writing instructions and educational materials during hospitalization and at discharge is the first fundamental step; however, these measures are inadequate and patients require follow-up [8]. Improper and inadequate follow-up of patients following their discharge may increase the risk of re-hospitalization within one month of discharge. However, unplanned re-hospitalization reflects the poor performance of the health system $[9$, 10]. Continuous follow-up is an integral part of the care services; thus, patients receiving follow-up programs are more likely to change their wrong health behaviors [11]. Regular remote follow-up helps patients to actively participate in the treatment process and successfully control their chronic diseases [12].

Therefore, all the attempts made for COPD patients have been valuable for treating them and improving their QoL. Thus, the present study aimed to determine the effects of the home-based self-care program follow-up on re-hospitalization frequency and QoL in COPD patients.

\section{Methods}

This was a quasi-experimental study with a pretestposttest and a control group design. The study population consisted of inpatients and patients visiting the clinic of Masih Daneshvari Hospital in Tehran City, Iran, in 2018. The required sample size was measured as 25 subjects based on similar studies using the following 
formula with a Confidence Interval (CI) of $95 \%$ and test power (1-B) of $80 \%$ :

$$
\begin{aligned}
& n=\frac{\left(z_{1-\frac{a}{2}}+z_{1-\beta}\right)^{2}\left(\sigma_{2}{ }^{1}+\sigma_{2}{ }^{2}\right)}{d^{2}}=\frac{(1.96+0.84)^{2}\left(7.13^{2}+845^{2}\right)}{(21.38-14.5)^{2}} \\
& =20.21=22 \\
& 222+3=25
\end{aligned}
$$

In total, 50 patients who met the inclusion criteria of the study were selected from the COPD patients. These patients had a history of hospitalization in the past 6 months and were randomly classified into 2 same-sized groups. During this study, 6 patients were gradually excluded from the study and finally, 44 patients (22/group) remained. Of the 6 patients, i.e., excluded from the study, 3 patients were excluded due to exacerbation, 2 were ruled out due to lack of cooperation, and 1 patient passed away.

The inclusion criteria were as follows: patients with COPD confirmed by a specialist; patients in the mild and moderate groups of the severity of disease, based on the COPD Assessment Test (CAT); a 6-month history of COPD; literacy; providing an informed consent form to participate in the research; an age range of 40-70 years; no underlying disease, such as cardiac psychological and musculoskeletal conditions that interfere with the selfcare program exercises. The exclusion criteria were the discontinuation of participation in the study by the patient for any reasons, such as death, relocation, as well as the development of other pulmonary and cardiac diseases.

In this study, the data gathering scales were as follows: the demographic characteristics questionnaire; COPD Assessment Test (CAT), and St. George's Respiratory Questionnaire (SGRQ):

COPD Assessment Test (CAT): CAT is an easy measure of assessing the effects of COPD on the health condition of patients, i.e., an inclusion criterion in this study. This questionnaire consists of 8 questions about cough, sputum, chest heaviness, dyspnea during activities, limited activity, sleep condition, patient's energy, and a sense of security when leaving the house. Each question has 6 score options (0-5) and the total score varies from 0 to 40. According to the score obtained, patients are classified into 4 groups; mild, moderate, severe, and extremely severe. In this study, the Persian version of this scale was applied to assess the health status of the explored COPD patients. The validity and reliability of this test were assessed by Sigari and Ghafouri in 2011 among COPD patients at Tohid Hospital in Sanandaj. The results of this study indicated that the Persian ver- sion of this questionnaire has a considerable Cronbach's alpha coefficient, i.e., in line with the results reported by Paul Jones, the designer of CAT $[13,14]$.

\section{St. George's Respiratory Questionnaire (SGRQ):}

This questionnaire consists of 50 questions classified into 3 categories. The first section includes pulmonary complaints and their sequence and severity. The second part covers activities that can lead to motor constraint and dyspnea. The third part addresses the effects of social performance and psychosocial conditions caused by a chronic respiratory disease, i.e., examined from different aspects. Each section of this inventory is ranked from 0 to 100 . If a patient selects the best answer to a question, which reflects a higher quality of life, the score is zero, and vice versa. The intermediate answers to each question are ranked from 0 to 100 considering the number of answers to the questions through apportioning. The SGRQ is a standardized tool designed to assess the QoL of patients with respiratory diseases [15]. A special version of this questionnaire is standardized to assess the QoL of COPD patients. The base scores on both versions (respiratory \& COPD diseases) are similar with a correlation coefficient of $0.99[16,17]$. The validity of the Persian version of the SGRQ, i.e., used in this study was confirmed in 2006 by Fallah Tafti et al. in COPD patients visiting Masih Daneshvari Hospital in Tehran. The Cronbach's alpha coefficient for the entire questionnaire was measured as 0.93 [18].

Initially, the demographic characteristics questionnaire and SGRQ (QoL) were completed by the research patients. Then, self-care training, including proper nutrition, stress reduction methods, pulmonary rehabilitation (deep breathing, pursed-lips breathing, \& diaphragmatic breathing) was provided to the study patients. The examined patients were randomly classified into the intervention and control groups. For the intervention group, a checklist of the home-based actions to continue the treatment was provided concerning self-care follow-up. Furthermore, they were exposed to 6 months of follow-up for the self-care program. In this period, phone calls were made fortnightly during the predetermined hours. Through these phone calls, the research participants were asked about the symptoms of the disease, including coughing, dyspnea, sputum, and fatigue after exercising as well as the respiratory exercises. Explanations and suggestions were also provided to the explored patients when necessary. Additionally, all the symptoms and explanations were recorded after each phone for follow-up questions in the subsequent phone calls. The checklist provided to the study patients to continue the treatment at home was prepared in two versions (the first trimester \& the second 
Table 1. The demographic information of the study participants

\begin{tabular}{|c|c|c|c|}
\hline \multirow{2}{*}{\multicolumn{2}{|c|}{ Variables }} & Control Group & Intervention Group \\
\hline & & N (\%) & N (\%) \\
\hline \multirow{2}{*}{ Gender } & Male & $16(72.72)$ & $14(63.63)$ \\
\hline & Female & $6(27.27)$ & $8(36.36)$ \\
\hline \multirow{3}{*}{ Age (y) } & $40-50$ & $5(22.72)$ & $6(27.27)$ \\
\hline & $51-60$ & $6(27.20)$ & $7(31.81)$ \\
\hline & $61-70$ & $11(50)$ & $9(40.90)$ \\
\hline \multirow{4}{*}{ Educational le } & Illiterate & $4(18.2)$ & $3(13.63)$ \\
\hline & Elementary school & $10(45.5)$ & $8(36.4)$ \\
\hline & Diploma & $4(18.2)$ & $6(27.3)$ \\
\hline & Academic & $4(18.2)$ & $5(22.7)$ \\
\hline \multirow{4}{*}{ The disease du } & 6 months & $1(4.5)$ & $2(9.1)$ \\
\hline & 6 months $-1 \mathrm{y}$ & $3(13.6)$ & $4(18.2)$ \\
\hline & $1-5$ & $6(27.3)$ & $5(22.7)$ \\
\hline & More than 5 & $12(54.5)$ & $11(50)$ \\
\hline
\end{tabular}

Пranian Rehabilitation Dournal

trimester). The examined patients had to perform all the activities daily and mark them on the checklist. The study patients were reminded of completing the checklists during each phone call. The required data were collected 3 times using the questionnaires (before, as well as $3 \& 6$ months into the follow-up program). The collected information was analyzed in SPSS v 22.

\section{Results}

The demographic data of the study participants indicated that the highest age-wise frequency belonged to the 61-70 years age group. Concerning gender, males shaped the highest frequency. Besides, most of the study participants had elementary school education. Moreover, the highest frequency regarding the disease duration was $>5$ years and the hospitalization frequency was once a year (Table 1).

According to the repeated-measures Analysis of Variance (ANOVA) data, there was a significant difference between the control and intervention groups. The etasquared calculated for the effect of the groups was equal to 0.49 , indicating that group membership explained $49 \%$ of the dependent variable variations. Furthermore, the F-value calculated for the stages equaled 24.60 , i.e., significant at 0.001 . Thus, there was a significant difference between the stages. The eta-squared calculated for the stages was 0.48 , indicating that $48 \%$ of the variations of the dependent variable were explained by the measurement time (before starting the follow-up program as well as $3 \& 6$ months after starting the follow-up program). Moreover, the F-value calculated for the effect of the interactions between the stages and the group was 30.05 , i.e., significant at 0.001 (Table 2). This finding indicated that the variations of $\mathrm{QoL}$ in the control and intervention groups differed in 3 test stages.

According to the Independent Samples t-test results, there was no significant difference between the mean scores of the study groups in the stage before starting the follow-up program. In other words, there was a lack of a significant difference between the study groups regarding QoL in this stage. In the second stage, i.e., 3 months after starting the follow-up program, there was a significant difference between the mean values of the study groups. This finding indicated that the mean score of the control group in this stage was larger than that of the intervention group; thus, it reflects the positive effects of the intervention on the decrease in the QoL score in the intervention group $(\mathrm{P}=0.001)$. Six months after the follow-up program onset, the mean group dif- 
Table 2. The ANOVA results on the difference between the study groups concerning the quality of life

\begin{tabular}{ccccccc}
\hline Sources of Variation & Sums of Squares & df & Mean of Squares & F & P & Partial Eta-squared \\
\hline Groups & 1674.10 & 1 & 1674.10 & 24.94 & 0.001 & 0.49 \\
\hline Error & 1744.78 & 26 & 67.10 & & & 0.48 \\
Stages & 288 & 2 & 144 & 24.60 & 0.001 & 0.54 \\
Groups* Stages & 351.71 & 2 & 175.85 & 30.05 & 0.001 & \\
\hline Error & 304.28 & 52 & 5.85 & & & \\
\hline
\end{tabular}

Iranian Rehabilitation Dourna|

ference was significant; therefore, the mean scores of the control group in this stage were higher than that in the intervention group $(\mathrm{P}=0.001)$ (Table 3$)$. Accordingly, after several months of intervention, the mean scores of the QoL of the intervention group were lower than that of the controls (a lower score reflects a higher QoL).

According to Table 4, there was a significant difference between the mean QoL scores of the intervention group in 3 stages. However, the mean QoL scores of the control group presented no significant decrease. We also compared the QoL scores of the period before the follow-up program and 6 after the follow-up program; there was a significant difference between the mean QoL scores of the intervention group. A positive value indicates a decrease in the mean score of QoL from the period before the follow-up program to 6 months into the follow-up program. This result reflects that the effectiveness of the provided self-care follow-up program remains constant over time. Thus, implementing the self-care program improves the QoL of the patients with COPD.

According to Table 5, the control group members were hospitalized once or more than once; however, 17(72\%) of the participants in the intervention group were not hospitalized at all 6 months into the intervention. Given the lack of normal distribution in the frequency of hospitalization, Mann-Whitney U test was employed. Considering the reported $\mathrm{z}$ statistic (i.e., an absolute value larger than 2) and the P-value, there was a significant difference in the effect of the actions taken in connection with the frequency of hospitalization of patients in the study groups $(\mathrm{P}=0.001)$.

\section{Discussion}

The current research results suggested that the self-care program follow-up reduced the re-hospitalization frequency and increased the QoL of the examined COPD patients. The pulmonary rehabilitation increases patients' tolerance for exercising and reduces the disease symptoms; therefore, the follow-up program in this study seems to have helped the patients perform their exercises; accordingly, it reduced the severity of the disease and the re-hospitalization frequency. Garcia-Aymerich et al. also revealed a strong relationship between physical activity and reduced hospitalization risk in COPD patients. [19]. Concerning COPD patients, for whom self-care and training are the goals of the rehabilitation interventions, the follow-up program in this study helped reduce the re-hospitalization frequency as an additional part of the rehabilitation programs. The research by Bourbeau et al. was in line with this finding. In this research, the COPD patients, who received training interventions through follow-ups, monitoring, and support per the self-care principles, provided better results regarding rehospitalization and QoL.

The researchers concluded that providing continuous self-care to COPD patients by a professional and trained

Table 3. Group-wise comparison of the mean quality of life scores in the research stages

\begin{tabular}{cccc}
\hline Stages & Comparing the Mean QoL Scores & SE & P \\
\hline Before starting the follow-up program & -1 & 2.19 & 0.13 \\
3 month after starting the follow-up program & -14.33 & 1.88 & 0.001 \\
6 month after starting the follow-up program & -15.66 & 1.69 & 0.001 \\
\hline
\end{tabular}


Table 4. Comparing the quality of life scores of study groups between the research stages

\begin{tabular}{ccccc}
\hline \multicolumn{1}{c}{ Stages } & Groups & Comparing the Mean QoL Scores & SE & P \\
\hline $\begin{array}{c}\text { Before and 3 months after starting the } \\
\text { follow-up program }\end{array}$ & Intervention & -14 & 1.37 & 0.001 \\
\hline $\begin{array}{c}\text { Before and 6 months after starting the } \\
\text { follow-up program }\end{array}$ & Control & 1.33 & 0.41 & 0.86 \\
\hline $\begin{array}{c}\text { Intervention } \\
\text { and 6 months after starting the follow- } \\
\text { up program }\end{array}$ & Intervention & -16 & 1.15 & 0.001 \\
\hline
\end{tabular}

Iranian Rehabilitation Journal

specialist can considerably reduce the re-hospitalization frequency and use of treatment services and improve patients' health [20]. COPD affects the patient's ability to perform their activities, which adversely affects the patient's QoL [21]. However, it seems the follow-up program helped the patients continuously conduct the exercises and correct their lifestyle; eventually, it will improve their QoL. Jokar et al. investigated COPD patients and indicated that home-based pulmonary rehabilitative nursing care led to a statistically significant increase in the QoL of these patients in a 7-week follow-up. Therefore, this program improved the QoL of these patients [22]. Moreover, Wang et al. reported that a continuous self-care program could improve the pulmonary performance and physical activity in COPD patients and increase their QoL [23].

Nietzsche et al. indicated that developing a self-care follow-up program was considerably more effective than the usual care in improving the health-related QoL and reducing reference frequency in COPD patients [24]. Seemingly, patients' commitment to self-care behaviors decreases following the mitigation of the severity of signs and symptoms over time.

\section{Conclusion}

Treatment is not solely aimed at the elimination of the physical signs and symptoms of the disease; thus, improving the patient's QoL has to be considered as well. If this need is overlooked, patients will lack motivation for making attempts and will perform fewer social activities. In this study, the self-care follow-up program considerably contributed to the improvement in the QoL of the explored patients. Therefore, it is recommended to include a self-care program and its follow-up at home, as an easy to administer, low-cost, and effective intervention, in the treatment plan for patients with COPD.

\section{Ethical Considerations}

\section{Compliance with ethical guidelines}

Research permission was obtained from the Ethics Committee of the University of Social Welfare and Rehabilitation Sciences (IR.USWR.REC.1397.041). All ethical principles were considered in this article. The participants were informed about the purpose of the research and its implementation stages.

Table 5. The frequency of hospitalization of patients in the intervention and control groups 6 months into the follow-up program

\begin{tabular}{ccc}
\hline \multirow{2}{*}{ Frequency of Hospitalization } & \multicolumn{2}{c}{ No. } \\
\cline { 2 - 3 } & Control Group & Intervention Group \\
\hline Without hospitalization & 0 & 17 \\
1 time & 16 & 5 \\
2 times & 5 & 0 \\
\hline times & 1 & 0 \\
\hline $\mathrm{P}=0.001 ; \mathrm{Z}=0.001$ & & Iranian Rehabilitation \ournal
\end{tabular}


Funding

This research did not receive any grant from funding agencies in the public, commercial, or non-profit sectors.

Authors' contributions

Conceptualization: Fatemeh Pazouki Movakher, Mohammad Saeed Khanjani; Methodology: Mohammad Saeed Khanjani, Mohammadali Hosseini; Investigation: Fatemeh Pazouki Movakher, Mohammad Saeed Khanjani, Banafsheh Ebrahimi Barmi; Writing - original draft: Fatemeh Pazouki Movakher, Mohammad Saeed Khanjani; Writing - review \& editing: All authors; Supervision: Mohammad Saeed Khanjani.

\section{Conflict of interest}

The authors declared no conflicts of interest.

\section{Acknowledgments}

The researchers appreciate the managers and employees of Masih Daneshvari Hospital and all patients who contributed to this study.

\section{References}

[1] Laviolette L, Lacasse Y, Doucet M, Lacasse M, Marquis K, Saey D, et al. Chronic obstructive pulmonary disease in women. Canadian Respiratory Journal. 2007; 14(2):93-8. [DOI:10.1155/2007/463435]

[2] Hassani M, Farahani B, Zohour A, Panahi Azar S. [Self-care ability based on Orem's theory in individuals with coronary artery disease (Persian)]. Journal of Critical Care Nursing. 2010; 3(2):15-6. http:/ /jccnursing.com/article-1-155-fa.html

[3] Abedi H, Salimi S, Feizi A, Safarivaghasloo S. [Assessment of relationship between self-efficacy and self-care in COPD patients (Persian)]. Journal of Nursing and Midwifery Urmia University of Medical Sciences. 2012; 10(1):68-74. http:// unmf.umsu.ac.ir/article-1-740-fa.html

[4] Gudmundsson G, Gislason T, Janson C, Lindberg E, Hallin $\mathrm{R}$, Ulrik CS, et al. Risk factors for rehospitalisation in COPD: Role of health status, anxiety and depression. European Respiratory Journal. 2005; 26(3):414-9. [DOI:10.1183/09031936.05 .00078504]

[5] Maslakpak MH, Raiesi Z. Effect of a self-management and follow-up program on self-efficacy in patients with multiple sclerosis: A randomized clinical trial. Nursing and Midwifery Studies. 2014; 3(4):e25661. [DOI:10.17795/nmsjournal25661] [PMID]
[6] Shojaee A, Nehrir B, Naderi N, Zareaeyan A. [Assessment of the effect of patient's education and telephone follow up by nurse on readmissions of the patients with heart failure (Persian)]. Iranian Journal of Critical Care Nursing. 2013; 6(1):29-38. http:/ /jccnursing.com/article-1-242-fa.html

[7] Ataee E, Haghjoo M, Dalvandi A, Bakhshandeh H. [Effect of self-care education on quality of life among patients with permanent pacemaker (Persian)]. Iranian Journal of Cardiovascular Nursing. 2013; 1(4):40-7. http://journal.icns.org.ir/ article-1-104-fa.htm

[8] Mistiaen P, Poot E. Telephone follow-up, initiated by a hospital-based health professional, for postdischarge problems in patients discharged from hospital to home. Cochrane Database of Systematic Reviews. 2006; 2006(4):CD004510. [DOI:10.1002/14651858.CD004510.pub3] [PMID]

[9] Pérez-Ferre N, Calle-Pascual AL. Overview of telemedicine applications in the follow-up of the diabetic patient. In: Graschew G, Roelofs T A, editors. Advances in Telemedicine: Applications in Various Medical Disciplines and Geographical Regions. London: InTech; 2011. [DOI:10.5772/14350]

[10] Laal N, Shekarriz-Foumani R, Khodaie F, Abadi A, Heidarnia MA. [Effects of patient education and follow up after discharge on hospital readmission in heart failure patients (Persian)]. Research in Medicine. 2017; 41(1):24-30. http:// pejouhesh.sbmu.ac.ir/article-1-1680-en.html

[11] Black JM, Hawks JH, Keene AM. Medical-surgical nursing: Clinical management for positive outcomes. Bengal: Elsevier India; 2009. https://www.google.com/books/ edition/Medical_Surgical_Nursing_Clinical_Manage/ TRqRtQEACAAJ?hl=en

[12] Maljanian R, Grey N, Staff I, Conroy L. Intensive telephone follow-up to a hospital-based disease management model for patients with diabetes mellitus. Disease Management. 2005 8(1):15-25. [DOI:10.1089/dis.2005.8.15]

[13] Jones PW, Brusselle G, Dal Negro RW, Ferrer M, Kardos P, Levy ML, et al. Properties of the COPD assessment test in a cross-sectional European study. European Respiratory Journal. 2011; 38(1):29-35. [DOI:10.1183/09031936.00177210]

[14] Sigari N, Ghafori B. [Reliability of Persian Version of COPD Assessment Test and its correlation with disease severity (Persian)]. Scientific Journal of Kurdistan University of Medical Sciences. 2013; 18(4):59-65. http://sjku.muk.ac.ir/article1-1188-fa.html

[15] Jones PW, Quirk FH, Baveystock CM. The St George's Respiratory Questionnaire. Respiratory Medicine. 1991; 85(Suppl B):25-31. [DOI:10.1016/S0954-6111(06)80277-5] [PMID]

[16] Jones PW. Health status measurement in chronic obstructive pulmonary disease. Thorax. 2001; 56(11):880-7. [DOI:10.1136/thorax.56.11.880]

[17] Meguro M, Barley EA, Spencer S, Jones PW. Development and validation of an improved, COPD-specific version of the St. George Respiratory Questionnaire. CHEST Journal. 2007; 132(2):456-63. [DOI:10.1378/chest.06-0702]

[18] Fallah Tafti S, Marashian SM, Cheraghvandi A, Emami H [Investigation of validity and reliability of Persian Version of the "St. George Respiratory Questionaire (Persian)]. Pajoohande. 2007; 12(1):43-50. http:// pajoohande.sbmu.ac.ir/ article-1-628-en.html 
[19] Garcia-Aymerich J, Farrero E, Felez M, Izquierdo J, Marrades R, Anto J. Risk factors of readmission to hospital for a COPD exacerbation: A prospective study. Thorax. 2003; 58(2):100-5. [DOI:10.1136/thorax.58.2.100]

[20] Bourbeau J, Julien M, Maltais F, Rouleau M, Beaupré A, Bégin $\mathrm{R}$, et al. Reduction of hospital utilization in patients with chronic obstructive pulmonary disease: A disease-specific self-management intervention. Archives of Internal Medicine. 2003; 163(5):585-91. [DOI:10.1001/archinte.163.5.585]

[21] Saeid M, Makarem A, Khanjani S, Bakhtyari V. Comparison of social Health and quality of life between the elderlies resident at nursing homes with non-resident counterparts in Tehran City, Iran. Salmand: Iranian Journal of Ageing. 2019; 14(2):178-87. [DOI:10.32598/sija.13.10.150]

[22] Jokar Z, Mohammadi F, Khankeh HR, Fallah Tafti S, Koushesh F. [Comparing home-based pulmonary rehabilitation nursing on fatigue and quality of life in patients with COPD (Persian)]. Journal of Fasa University of Medical Sciences. 2014; 4(2):168-76. http://jabs.fums.ac.ir/article-1-646-en.html

[23] Wang L, Mårtensson J, Nygårdh A, Zhao Y. Experiences of a health coaching self-management program in patients with COPD: A qualitative content analysis. International Journal of Chronic Obstructive Pulmonary Disease. 2018; 13:1527-36. [DOI: 10.2147/COPD.S161410] [PMID] [PMCID]

[24] Newham JJ, Presseau J, Heslop-Marshall K, Russell S, Ogunbayo OJ, Netts $\mathrm{P}$, et al. Features of self-management interventions for people with COPD associated with improved healthrelated quality of life and reduced emergency department visits: A systematic review and meta-analysis. International Journal of Chronic Obstructive Pulmonary Disease. 2017; 12:1705-20. [DOI:10.2147/COPD.S133317] [PMID] [PMCID] 